\title{
Políticas educacionais para o Ensino Médio: a inclusão educacional/exclusão social como intenção e gesto
}

\author{
Educational policies for Middle School: educational inclusion/social \\ exclusion as intention and gesture
}

\section{Políticas educacionales para la Enseñanza Medio: la inclusión educacional/exclusión social como intención y gesto}

\section{Aparecida Favoreto'}

Universidade Estadual do Oeste do Paraná, Docente Pesquisadora do Mestrado em Educação e do Colegiado de Pedagogia; Membro do Grupo de Pesquisa História e Historiografia na Educação

\section{Ireni Marilene Zago Figueiredo ${ }^{2}$}

Universidade Estadual do Oeste do Paraná, Docente Pesquisadora do Mestrado em Educação e do Colegiado de Pedagogia; Membro do Grupo de Estudos e Pesquisas em Política

Educacional e Social

\section{Roberto Antonio Deitos ${ }^{3}$}

Universidade Estadual do Oeste do Paraná, Docente Pesquisador do Mestrado em Educação e do Colegiado de Pedagogia; Membro do Grupo de Estudos e Pesquisas em Política

Educacional e Social

Resumo: Neste artigo apresenta-se uma reflexão sobre os significados políticos dos projetos e programas de reformas educacionais para o Ensino Médio posteriores ao fim da Ditadura Militar (19852017), tendo como problemática o discurso de que uma educação de qualidade poderia favorecer a democracia. A análise dos dados do estudo teve como base os documentos e dados expedidos pelo Governo Federal, bem como os intérpretes da história sócio-política, principalmente no que se refere às reformas da Educação, do Estado brasileiro e ao movimento do capitalismo nacional e internacional, evidenciando uma lacuna entre o proposto pelos documentos e os resultados implementados. Destacase que as reformas educacionais se adequaram às mudanças tecnológicas e à crise do capital, com relação ao processo de inclusão/exclusão social.

Palavras-chave: Políticas educacionais. Reforma do Estado. Democracia e inclusão/exclusão social.

Doutora em Educação pela Universidade Federal do Paraná; Mestre em Educação pela Universidade Estadual de Maringá; https://orcid.org/0000-0003-3883-5604; http://lattes.cnpq.br/3103506424875004.

2 Doutora em Educação pela Universidade Estadual de Campinas; Mestre em Educação pela Universidade Estadual de Campinas; https://orcid.org/0000-0001-8875-7099; http://lattes.cnpq.br/0727859600733159.

3 Doutor em Educação pela Universidade Estadual de Campinas; Mestre em Educação pela Universidade Estadual de Campinas; https://orcid.org/0000-0001-9150-6354; http://lattes.cnpq.br/4743456433918126. 
Abstract: This article presents a reflection on the political meanings of the projects and programs of educational reforms for High School, after the end of the Military's Dictatorship period (1985-2017). It introduces as a problematic the argument that a quality education could enable the democracy. The analysis of this article was based on the documents and information provided by the Brazilian Federal Government as well as the interpreters of the social political history. It was given an especial attention to the reforms of Education and Brazilian State, also the national and international capitalism cycle, evidencing a gap between the proposed by the documents and the results implemented. It is emphasized, then, taking as reference the process of social inclusion/exclusion, that the educational reforms were adapted to the technological changes and the crisis of the capital.

Keywords: Educational policies. Reform of the State. Democracy and inclusion/social exclusion.

Resumen: En este artículo se presenta una reflexión sobre los significados políticos de los proyectos y programas de reformas educativas para la Enseñanza Media, posteriores al final de la Dictadura Militar (1985-2017), teniendo como problemática el discurso de que una educación de calidad podría favorecer la democracia. El análisis de los datos tuvo como base los documentos y datos expedidos por el Gobierno Federal, así como los intérpretes de la historia sociopolítica, principalmente en lo que se refiere a las reformas de la Educación, del Estado brasileño y el movimiento del capitalismo nacional e internacional, evidenciando una laguna entre el propuesto por los documentos y los resultados implementados. Se destaca, entonces, que las reformas educativas se adecuaron a los cambios tecnológicos ya la crisis del capital, con relación al proceso de inclusión/exclusión social.

Palabras clave: Políticas educativas. Reforma del Estado. Democracia e inclusión/exclusión social.

Recebido em 30 de janeiro de 2018

Aceito em 30 de outubro de 2018

Publicado em 19 de fevereiro de 2019

\section{INTRODUÇÃO}

Este artigo traça reflexões sobre os significados políticos dos projetos e programas de reformas educacionais defendidas e efetivadas após o período da Ditadura Militar no Brasil (1985), tendo como problemática o discurso de que uma Educação de qualidade poderia favorecer a democracia. ${ }^{4}$ Para a análise dessa problemática, tomam-se por base pesquisas

4 Para Bobbio, Manteucci e Pasquino (2000), o termo democracia é muito complexo e possui significados diferentes, conforme a época e o teórico que a ele se refere. No que se refere à educação, a perspectiva educação para a democracia não é diferente. Na história da educação brasileira, para além de ser um dos temas constantemente citado, tal perspectiva já foi 
de diversos teóricos da área, que estão publicadas em livros e/ou artigos científicos, além de documentos e dados oficiais expedidos pelo Governo Federal. Neste caso, são priorizados alguns intérpretes da história sócio-política que estabeleceram relações entre as reformas educacionais e o contexto histórico das últimas décadas.

Para realizar o proposto, em um primeiro momento, apresentam-se alguns índices educacionais brasileiros da década de 1980 e atuais, em que, traçando comparações, questiona-se a tese de que a educação de qualidade poderia promover a democracia. № segundo momento, busca-se analisar o teor da política educacional brasileira com relação ao processo de reformulação do Estado e do modelo de produção. Nesse sentido, colocando em destaque o Ensino Médio, assinalando as contradições da política capitalista, pontua-se como se sustentou a necessidade de reformas do Estado e da educação, bem como a confluência destas com os organismos internacionais e o processo de expansão e acumulação do capital nacional e internacional.

Com base nessas reflexões, pontuam-se alguns aspectos ou tendências sobre o que mudou e o que permaneceu nas políticas educacionais brasileiras com o fim da Ditadura Militar. Assim, objetiva-se compreender o embate educacional para além das palavras convincentes e levantar elementos para refletir sobre os problemas educacionais no contexto mais amplo das contradições inerentes ao processo do capitalismo e das reformas em curso.

\section{QUESTÃO PROBLEMA}

Com o fim da Ditadura Militar, ao se propagar o processo de abertura política no Brasil, inflamados debates ocorreram em torno dos objetivos educacionais, entre os quais se sobressaiu o discurso de que uma educação de qualidade poderia favorecer a democracia. Nessa perspectiva, no mínimo duas correntes de pensamento vislumbravam mudanças com relação a uma Educação de qualidade como fator de ruptura com o passado autoritário e excludente da Ditadura Militar. Ambas se assemelhavam no desejo de uma educação de qualidade para a democracia, entretanto mostravam concepções diferentes de sociedade e de formação.

\footnotetext{
título de livros que marcaram época, como: Democracia e Educação, de John Dewey, primeira tradução publicada no Brasil em 1936; Educação para a democracia de Anísio Teixeira, publicado pela primeira vez em 1935; Escola e democracia, de Dermeval Saviani, o qual foi publicado pela primeira vez em 1983. Atualmente, de forma crítica ou não, ainda continua sendo um tema discutido, além de estar anunciado nas perspectivas das políticas educacionais nacionais e diretrizes indicadas pelo Banco Mundial, o qual aponta a educação como elemento que pode promover o desenvolvimento social, ser impulso ao crescimento econômico, aumentar a coesão da sociedade, oferecer melhores oportunidades aos indivíduos e reduzir a pobreza. Maiores informações consultar Mota Junior e Maués (2014).
} 
Das duas tendências que predominaram nos debates sobre a questão educacional, uma priorizou a formação humana, destacando a consciência crítica como possibilidade de transformar a sociedade, de modo a torná-la mais igualitária social e economicamente. ${ }^{5} \mathrm{~A}$ outra preconizou a formação de qualidade para o trabalho, concebendo-a como possibilidade de contribuir para a redução da desigualdade e da pobreza dos países e dos indivíduos.

Apesar de a primeira tendência ser constantemente citada nos debates educacionais, essa última predominou nos projetos de reformas educacionais. Nesse sentido, em meio à defesa de que o Estado deveria passar por ajustes econômicos e políticos, argumentou-se que a educação deveria se adequar ao ritmo do mercado de trabalho. $A$ defesa da formação de qualidade para o trabalho passou a ser constantemente citada, tendo como fundamento o acelerado processo de mudanças tecnológicas e a internacionalização do capitalismo. Reafirmou-se a Teoria do Capital Humano, destacando-se que a elevação dos níveis de escolaridade poderia aliviar a pobreza e aumentar a capacidade produtiva do País.

Assim, a década de 1990 e as subsequentes são marcadas com a proposição de diversos programas e projetos educacionais, inclusive com o financiamento dos organismos internacionais, entre os quais o Banco Internacional para a Reconstrução e o Desenvolvimento (BIRD), o Banco Mundial (BM) e o Banco Interamericano de Desenvolvimento (BID). Em paralelo a esse processo, seguindo as decisões tomadas na Conferência Mundial de Educação para Todos de Jomtien, Tailândia (1990), a avaliação em larga escala ganhou força, sendo entendida como condição necessária para tornar a educação básica equitativa e como forma de oferecer as oportunidades para que todos os países alcançassem e mantivessem um padrão mínimo de qualidade da aprendizagem.

No que se refere ao Ensino Fundamental, pode-se inferir que os financiamentos internacionais e as políticas educacionais adotadas contribuíram para a sua quase universalização, visto que a taxa de escolarização em 2016 entre pessoas de 6 a 14 anos chegou a 99,2\% (BBGE, 2017a). ${ }^{6}$ Uma conquista de suma importância, visto que, para pensar sobre a educação básica e suas modalidades, o Ensino Fundamental é de grande valor.

No que se refere ao Ensino Médio, é necessário destacar que a Constituição Federal de 1988, Art. 208, especificou que esse nível de ensino teria progressiva extensão da obrigatoriedade e da gratuidade e, em 1996, pela emenda Constitucional n. 14, definiu que o Ensino Médio teria progressiva universalização e gratuidade. Nesse processo, este teve um significativo índice quantitativo, como é anunciado pelo Centro de Políticas Públicas do Insper (2017), o qual afirma que em 
[...] 2015 quase $99 \%$ da população de 7 a 14 anos de idade frequentava a escola. Outra tendência verificada é da redução do atraso escolar, que faz com que as fronteiras entre as áreas se tornem mais verticais, principalmente no Ensino Fundamental e no Ensino Médio (ENSINO SUPERIOR EM NEGÓCIOS, DIREITO E ENGENHARIA, 2017, p. 4).

Entretanto, em que pesem os números atingidos em 2015, a realidade educacional atual tem excluido os trabalhadores brasileiros dos bens econômicos e culturais. Comparando os dados educacionais de $1985 \mathrm{com}$ a atualidade, observa-se que houve um salto quantitativo. A título de demonstração, em 1980, 14,\% da população brasileira havia concluído o Ensino Médio (INSTITUTO NACIONAL DE ESTUDOS E PESQUISAS EDUCACIONAIS ANISIO TEIXEIRA, 2001), e, em 2015, esse percentual atingiu 31,1\% (ORGANISATION FOR ECONOMIC CO-OPERATION AND DEVELOPMENT, 2015).

Entretanto, se o número de matrículas e de acesso ao Ensino Médio tem crescido, os dados qualitativos com relação à proficiência de Língua Portuguesa e de Matemática têm sido alvo de preocupação. Essa afirmação pode ser constatada quando o Sistema de Avaliação da Educação Básica (SAEB), tomando por base os dados fornecidos pelo Instituto Nacional de Estudos e Pesquisas Educacionais Anísio Teixeira (2016) e comparando 1995, 2005 e 2015, divulgou a redução dos índices atingidos pelos alunos do Ensino Médio nos referidos componentes curriculares:

Gráfico 1 - Desempenho médio de estudantes brasileiros por área de conhecimento em 1995, 2005 e 2015

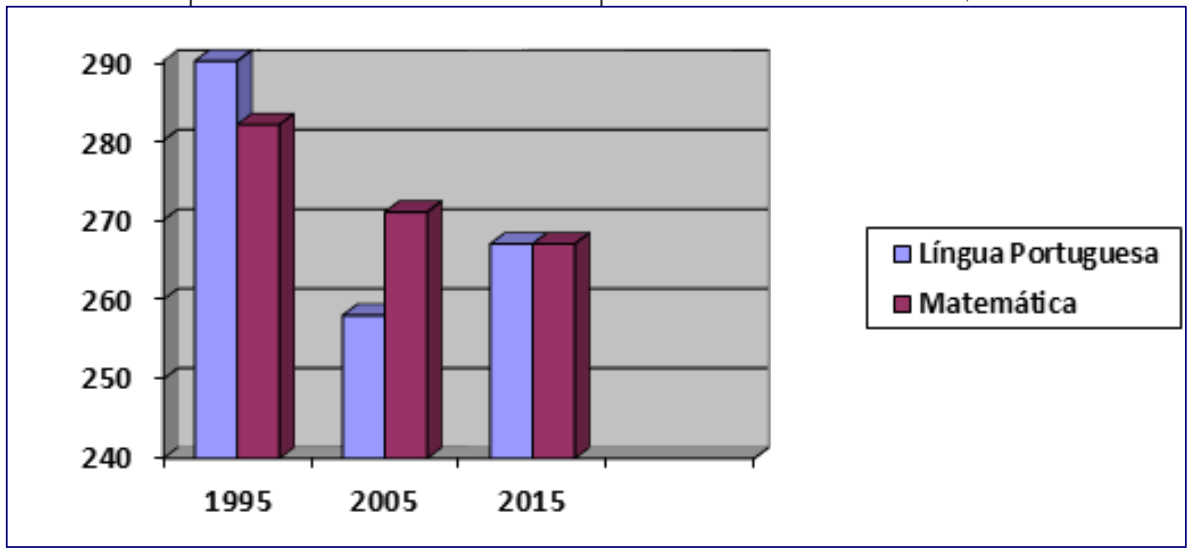

Fonte: Instituto Nacional de Estudos e Pesquisas Educacionais Anísio Teixeira (2016).

No mesmo sentido, o Centro de Políticas do Insper, também com base nos dados fornecidos pelo Inep, afirma que apesar de outros níveis do ensino terem apresentado relativa 
melhora no desempenho dos alunos, o Ensino Médio apresentou declínio em 2015. Conforme o Insper (2017):

\begin{abstract}
Para se ter uma ideia da evolução da qualidade da Educação Básica, utilizamos as médias de proficiência em Língua Portuguesa e em Matemática do SAEB [...] Podemos verificar que houve uma queda na média em Língua Portuguesa de 1995 para 1999 nas três séries abrangidas pela avaliação, que coincide com o período de expansão das matrículas. As médias do $5^{\circ}$ ano do Fundamental apresentam crescimento gradual até 2015, superando as médias do início do período. 0s estudantes do $9^{\circ}$ ano do Fundamental e do $3^{\circ}$ ano do Médio apresentaram uma pequena melhora no desempenho no final dos anos 2000, com relativa estagnação posterior. Em 2015 os estudantes do $9^{\circ}$ ano apresentaram uma ligeira melhora das notas. Já a proficiência em Matemática manteve-se praticamente constante ao longo dos anos analisados para $\circ 3^{\circ}$ ano do Ensino Médio, apresentando indicios de queda no desempenho nos anos mais recentes. Tanto $\circ 5^{\circ}$ ano quanto - $9^{\circ}$ ano do Fundamental apresentaram suas melhores notas no exame em 2015. (ENSINO SUPERIOR EM NEGÓCIOS, DIREITO E ENGENHARIA, 2017, p. 47).
\end{abstract}

Da mesma forma, os resultados alcançados em 2015 pelo Brasil no Programa Internacional de Avaliação de Estudantes (Pisa, na sigla em inglês) ${ }^{7}$ também mostram resultados preocupantes. Há uma queda de pontuação nas três áreas avaliadas: Ciências, Leitura e Matemática, o que resultou também em queda do Brasil no ranking mundial, pois, de 70 países, o País ficou na $63^{a}$ posição em Ciências, na $59^{a}$ em Leitura e na $66^{a}$ colocação em Matemática, ficando aquém de países como Singapura, Finlândia, Uruguai e Chile. Aliás, nas três áreas avaliadas, mais da metade dos estudantes brasileiros ficaram abaixo do nivel 2, o qual é considerado pela Organização para a Cooperação e Desenvolvimento Econômico (OCDE), o básico para "[...] a aprendizagem e a participação plena na vida social, econômica e cívica das sociedades modernas em um mundo globalizado." (MORENO, 2016).

As causas apontadas para o baixo rendimento nos componentes curriculares anteriormente analisados são muitas. Há quem pontue a formação dos professores, a falta de empenho dos alunos, das famílias, etc. Certamente, o empenho de cada um é importantíssimo, mas, em se tratando do desenvolvimento educacional do País em um contexto internacional, tais justificativas não parecem plausiveis. Os dados nos fazem refletir sobre o discurso da 
educação de qualidade para a democracia, e, neste aspecto, com base em Mota Junior e Maués (2014, p. 1150), destaca-se que

\begin{abstract}
[...] os altos índices de analfabetismo funcional, mesmo que diante de uma redução no analfabetismo absoluto, os baixos resultados dos estudantes e escolas brasileiros nas avaliações nacionais e internacionais [...], o crescimento da violência nas escolas, os baixos salários dos trabalhadores em educação e a manutenção de problemas históricos e estruturais relacionados ao financiamento público e à precarização das condições de trabalho, entre outros, são elementos da realidade que nos permitem relativizar e questionar a suposta educação de nível mundial que o Brasil estaria atingindo.
\end{abstract}

Noutros termos, o que se evidencia é a fragilidade da tese que a educação de qualidade poderia promover a democracia, principalmente no que se refere à defesa de que as reformas educacionais ampliariam as oportunidades educacionais e, consequentemente, proporcionariam maior acesso aos bens culturais e econômicos.

Ainda sobre o Ensino Médio, é necessário considerar que, para além de ser a última etapa da educação básica, ele se constitui um dos requisitos para concorrer em concurso público, bem como tem sido, cada vez mais, uma exigência das empresas para efetivar a contratação em setores de média e baixa exigência de qualificações profissionais. Diante de tal exigência sobre o trabalhador, grande parte daqueles que estão defasados na idade-série tem dado preferência à Educação de Jovens e Adultos (EJA), cuja matrícula cresceu 21\% no período 2001-2005, três vezes mais do que o curso médio regular (INSTITUTO DE PESQUISA ECONÔMICA APLICADA, 2006, p. 197). ${ }^{8}$ Uma preferência de estudo que se alia, geralmente, a uma jornada de trabalho de 44 horas semanais. Nesta dupla, e por vezes tripla jornada de trabalho, ${ }^{9}$ o tempo dedicado aos estudos é reduzido significativamente, ou seja, ocorre a divisão do tempo de estudo com as extenuantes jornadas de trabalho. Neste aspecto, apenas aqueles que possuem uma maior renda familiar conseguem permanecer mais tempo na escola (INSTITUTO DE PESQUISA ECONÔMICA APLICADA, 2006, p. १28).

Com relação à distorção idade-série no Ensino Médio, os índices brasileiros são muito altos..$^{10}$ Oshima (2015), com base em dados divulgados pela OCDE, em um artigo publicado

8 De acordo com o Instituto de Pesquisa Econômica Aplicada (2006), para os jovens e adultos ocupados ou em busca de trabalho, a EJA é não apenas o caminho mais rápido, mas também mais atrativo do que o ensino médio regular, em virtude de ambientes, horários e, em alguns casos, de metodologias mais ajustadas ao seu perfil, como o Telecurso 2000, o Tecendo - Saber e a Escola da Juventude. Segundo o relatório do Ensino Superior em Negócios, Direito e Engenharia (2017, p. 41), até 2015, as matrículas na EJA tiveram menos variação e permaneceram no patamar próximo a um milhão.

9 Alguns estudantes, principalmente as mulheres, além do emprego e estudos, dedicam-se aos cuidados da casa e da família

10 No que se refere à distorção idade-série, ela também pode ser um dos implicadores no baixo desempenho dos alunos brasileiros nas avaliações do Pisa, pois, estando matriculados em uma unidade de ensino, entre seus 15 anos e 3 meses 
na Revista Época, afirma que o "Brasil está na lanterna" quando se trata de oportunidade de educação na idade certa. Ainda sobre a distorção idade-série, o Instituto Nacional de Estudos e Pesquisas Educacionais Anísio Teixeira (2017, p. 21), em análise aos dados de abandono e de reprovação no Ensino Médio, destaca que "Observa-se que apesar dos alunos das redes pública e privada apresentarem um risco similar de insucesso no primeiro ano do ensino fundamental, nas séries subsequentes o risco de insucesso dos alunos matriculados na rede pública é consideravelmente superior."

No caso, apesar de as políticas educacionais posteriores à queda da Ditadura Militar se caracterizarem pelo discurso da educação de qualidade para promover a democracia, a exclusão dos alunos de baixa renda continua a ser uma realidade.

Nesse aspecto, mesmo que as reformas educacionais implementadas nas últimas décadas tenham sido justificadas pela necessidade de formar para o trabalho, elas precisam ser analisadas considerando também os excluidos do processo de trabalho e da escola. Para isso, é necessária uma leitura crítica da produção capitalista. Para além do indivíduo ou da proposição grifada no corpo da Lei, é necessário verificar como se constitui o desenvolvimento do sistema capitalista, o qual tem na expropriação da classe trabalhadora as condições necessárias para manter sua reprodução. Nesse sistema contraditório estão localizadas as políticas educacionais. Para superar essa condição, é preciso compreendê-las, atentando para a totalidade do movimento contraditório do capitalismo. Nesse sentido, buscase apoio em alguns estudos críticos das políticas educacionais implementadas, principalmente, as posteriores à década de 1990.

\section{OS ORGANISMOS INTERNACIONAIS, AS REFORMAS EDUCACIONAIS E O ENSINO MÉDIO}

Após 1964, ○ Estado brasileiro aprofundou as relações com o capitalismo internacional. Deitos (2005, p. 206) afirma que as décadas de 1960, 1970 e parte da década de 1980

\footnotetext{
[...] expressam a consumação do processo de internacionalização da economia brasileira sustentada politicamente pelo golpe miltar de 1964, movida pela concentração de riqueza, endividamento externo e interno, "milagre econômico", contracenando com a miséria e a repressão politica.
}

(completos) e 16 anos e 2 meses (completos), estejam cursando no mínimo a $7^{\circ}$ série/ano, realizam os exames, mesmo estando nas séries inferiores às correspondentes para suas idades. 
Nesse período (1964-1985), segundo Fagnani (1999, p. 155), o Estado brasileiro é "marcado pela implementação de uma estratégia conservadora", a tal ponto que, com o passar do tempo, repercutiu na concentração de renda. Segundo Vieira (1983, p. 208):

[... A participação na renda, dos $50 \%$ mais pobres da população economicamente ativa, caiu de $17,71 \%$ (em 1960) para 14,91\% (em 1970), descendo ainda mais para 11,8\% (em 1976). Em sentido contrário, a participação dos $5 \%$ mais ricos da população economicamente ativa aumentou de $27,69 \%$ (em 1960) para $34,86 \%$ (em 1970), elevando-se aos poucos para $39 \%$ (em 1976) da renda.

Se, durante a Ditadura Militar, a tese apresentada é de que primeiramente deverse-ia "fazer o bolo crescer, para depois dividi-lo"," lançada na década de 1980, logo se vê, o seu relativo progresso econômico sendo devorado, com implicações sociais, econômicas e políticas. Chasin (1986) destaca que, no final da Ditadura Militar, apesar de o Brasil ocupar o $8^{\circ}$ lugar na economia mundial, o poder de compra da população ocupava a $54^{\circ}$, enquanto a metade da renda nacional ficava com $\uparrow$ da população mais rica.

No que se refere à educação, Germano (1994, p. 22) destaca que apesar de toda propaganda dos governos militares, os quais usavam a "política educacional como estratégia de hegemonia, [o Estado] deixou de cumprir uma das principais funções" de Estado capitalista: "assegurar a escolarização da força de trabalho." Nesse sentido, ressalta-se que a Ditadura Militar deixou uma dramática herança educacional. Segundo Germano (1994):

\footnotetext{
Em 1985, o MEC divulga que existem "20 milhões de analfabetos no pais - 1/4 da população com idade igual ou superior a 15 anos -, cerca de 8 milhões de crianças em idade escolar jamais tiveram acesso à escola ou dela se afastaram precocemente [...] Essa situação é tanto crítica quanto se verifica sua exacerbação nos anos recentes. Com efeito, na década de 1970, pela primeira vez nos últimos 50 anos, as matrículas das quatro séries iniciais do $1^{\circ}$ grau cresceram em ritmo inferior à população' (MEC, 1985:4, grifos nossos). Fato que se agrava quando se constata, conforme estudo realizado pelo IBGE e pela Unicef, que, em 1986, 30\% da população (15 milhões em números absolutos), entre 10 e 17 anos, integrava o mercado de trabalho, um dos mais fortes motivos de ausência à escola. A maioria com jornada de trabalho igual ou superior a 40 horas semanais, não possuíam carteira assinada e recebia, em média, apenas $20 \%$ de um salário mínimo por mês. (DIMENSTEIN, 1989 apud GERMANO, 1994, p. 269, grifo do autor).
}

" Palavras de Antônio Delfim Netto, então Ministro da Fazenda de Costa e Silva (1967-1969) e de Médici (1969-1973) (FOLHA DE SÃO PAULO, 2008). 
Diante dessa realidade, nos anos iniciais da Nova República, anunciou-se que, junto com a abertura política, seria necessário retomar o crescimento econômico brasileiro, reduzir a pobreza, ampliar a oferta e melhorar a qualidade da educação. Na direção dessas mudanças, ocorreu um processo amplo de reformas políticas ${ }^{12}$ e econômicas ${ }^{13}$ decorrentes das condicionalidades dos empréstimos para os ajustes estruturais (1980) e setoriais (1983). Porém, apesar das reformas, no período de transição democrática (1985/90), as contradições produzidas nas décadas anteriores permaneceram.

Fiori (1995, p. 184), ao tratar sobre esse processo, afirma que houve uma dinâmica conservadora no fim da década de 1970 e início da década de 1980:

\begin{abstract}
[...] 0 processo então iniciado, que poderíamos chamar de retomada da hegemonia norte-americana, começa mais uma vez pelo lado da moeda, e só chega aos canhões em sua fase final. Subindo suas taxas de juros internas, com vistas à revalorização do dólar para reverter a situação de decadência financeira norte-americana, o governo dos Estados Unidos e o FED iniciaram o que ficou conhecido como diplomacia do dólar forte. Ela foi responsável, imediatamente, por uma desvalorização desigual das demais moedas, seguida de uma crise financeira global da economia. Os ajustes econômicos obrigatórios das diversas economias nacionais a esta nova realidade foram os grandes responsáveis - junto com o segundo choque do preço do petróleo - pelo movimento recessivo generalizado que atravessou a economia mundial durante os primeiros anos da década de 80.0 resultado, em todo lugar, foi a deterioração da situação das finanças públicas e o desemprego generalizado.
\end{abstract}

Nesse sentido, Laurell (2002), ao analisar o desenvolvimento do capitalismo no final do século XX, observou que o cenário era de uma crise estrutural global e de políticas de ajuste econômico, o que acarretou no aumento do desemprego, da miséria e da exclusão social, ao ponto que "[...] cerca de $50 \%$ dos latino-americanos" foram considerados miseráveis, ou seja, "[...] a não-satisfação do mínimo em alimentação, habitação, saúde e educação." (LAURELL, 2002, p. 167).

Analisando esse período, Fagnani (1999, p. 155-156) destaca que a transição democrática (1985/90) foi conduzida de forma “[...] negociada por uma ampla e heterogênea

12 Nesse período, para além da reforma do sistema representativo-partidário, conhecido como redemocratização, fala-se na necessidade de implementar o Estado mínimo no Brasil, ou seja, com base nas teorias neoliberais defende-se a não intervenção do Estado nas atividades comerciais e a descentralização política, bem como a chamada da sociedade civil para participar da formação dos Conselhos Comunitários.

B As propostas de reorganização na área econômica têm como objetivo: expandir o processo de privatização; estimular a competitividade e as exportações; redução do custo da produção; flexibilização da legislação trabalhista; redução dos encargos sociais; aumento da poupança interna, etc. 
coalizão de forças políticas, selando um novo pacto conservador entre as elites." Uma forma de conduzir a política que se repetiu na década de 1990 e nas subsequentes.

Sobre esse processo, Deitos (2005) afirma que as políticas econômicas buscaram assegurar a hegemonia do capital no País, enquanto o setor produtivo, em meio ao declínio do modelo taylorista-fordista, buscou novas alternativas de produção para enfrentar a crise estrutural do capitalismo. Uma forma de conduzir a economia e a produção que influenciou as propostas de reformas educacionais. No caso, diante do quadro de crise do capitalismo e de miséria da maioria da população da América Latina, os organismos internacionais emitiram algumas proposições de ajustes para a educação, havendo um alinhamento entre o Ministério da Educação do Brasil (MEC) e o Banco Mundial.

Entre as diversas análises e propostas de ajustes emitidos pelo Banco Mundial, a razão da miséria era especificada como uma falta de ajuste cultural e comportamental às novas exigências da produção capitalista. Neste caso, a redução significativa da pobreza seria resultado de "[...] um grande empenho no sentido de melhorar a educação, [... especialmente se for possível melhorar a focalização dos recursos." (BANCO MUNDIAL, 2001, p. 11, grifo do autor).

De modo geral, o capitalismo passou por uma reorganização na sua forma de acumulação, em que a flexibilidade como nova forma de gestão da produção, passou a se confrontar com rigidez do fordismo. Segundo Harvey (2002), trata-se de uma reorganização que se apoia

\footnotetext{
[...] na flexibilidade dos processos de trabalho, dos mercados de trabalho, dos produtos e padrões de consumo. Caracteriza-se pelo surgimento de setores de produção inteiramente novos, novas maneiras de fornecimento de serviços financeiros, novos mercados e, sobretudo, taxas altamente intensificadas de inovação comercial, tecnológica e organizacional. A acumulação flexível envolve rápidas mudanças dos padrões de desenvolvimento desigual, tanto entre setores como entre regiões geográficas, criando, por exemplo, um vasto movimento no emprego no chamado setor de serviços, bem como conjuntos industriais completamente novos em regiões até então subdesenvolvidas [...] Ela também envolve um novo movimento [...] no mundo capitalista - os horizontes temporais da tomada de decisões privada e pública se estreitaram, enquanto a comunicação via satélite e a queda dos custos de transporte possibilitaram cada vez mais a difusão imediata dessas decisões num espaço cada vez mais amplo e variegado. (HARVEY, 2002, p. 140).
}

Emergiram, assim, novos processos de trabalho "[...] onde o cronômetro e a produção em série e de massa são substituídos pela flexibilização da produção, pela especialização flexível, por novos padrões de busca de produtividade, por novas formas de adequação da produção à lógica de mercado." (ANTUNES, 1999, p. 16, grifo do autor). 
Muitas teses sobre a necessidade de reformas educacionais foram defendidas, entre as quais, nas políticas implementadas pelos órgãos federais, sobressaiu a tese de que a reforma curricular do Ensino Médio era uma necessidade urgente. Pontuou-se que as modificações no processo produtivo impunham a formação de "novas" habilidades e competências. Assim, a reforma curricular deveria responder a essas "novas" exigências, desenvolvendo habilidades e competências para o trabalho e para as vivências sociais.

Diante da reestruturação da produção e suas consequências no mercado mundial, inclusive com o acirramento da competitividade empresarial global, julgou-se necessária a aquisição de novas habilidades e competências, bem como pontuou-se a necessidade de novos conteúdos. Defendeu-se, nesse caso, que a escola deveria assegurar uma nova pedagogia, mais dinâmica e flexível.

De fato, o elevado grau de competitividade ampliou a demanda por
conhecimentos e informaçães e, consequentemente, a educação foi eleita
como barreira estratégica para fazer face à velocidade das mudaç̧as.
[... Se o mundo virou pelo avesso, a educação deve acompanhá-lo na
reviravolta. Caem em desuso a escola tradicional, a educação formal, as
antigas referências educacionais. 0 discurso é claro: é preciso, agora,
elaborar uma nova pedagogia, um projeto educativo de outra natureza, e
assegurar o desenvolvimento das competências [...] (MORAES, 2003, p. 152).

Tal projeto educativo passa a valorizar o desenvolvimento das capacidades subjetivas, as habilidades intelectuais, cognitivas e comportamentais, as quais se firmam na defesa do desenvolvimento das competências por intermédio da formação escolar.

Segundo Ramos (2001), nesse debate, o conceito de competência assume a centralidade, contrapondo-se ao de qualificação anteriormente utilizada para designar formação do trabalhador na perspectiva taylorista-fordista. A competência profissional passa a ser entendida como os conhecimentos, as habilidades e as atitudes que são mobilizados pelos trabalhadores para a realização de uma ação específica, contrapondo-se à ideia de que qualificação depende da bagagem cultural acumulada na vida profissional aliada à formação escolar. Segundo Ramos (2001, p. 61-62):

[...] o sistema de classificação, carreira e salário baseados nos diplomas, portanto, em profissões bem definidas, seria inadequado à instabilidade das ofertas de empregos e a uma gestão plena no interior das organizações. Isso porque a qualificação repousa sobre repertórios relativamente estáveis: os postos de trabalho, cuja possessão é combinação de direitos precisos e duráveis e não podem ser questionado. 
Coloca-se, dessa forma, em dúvida o valor dos diplomas, a possibilidade de sobreviver de uma profissão bem delimitada, bem como diminuem-se as expectativas quanto a uma biografia profissional linear. Por outro lado, a dimensão experimental passa a ser valorizada, ou seja, o saber fazer encontra eco na noção de competência.

Nesse conjunto de mudanças, associadas às aceleradas inovações no sistema produtivo e ao crescente índice de desemprego, a noção de competência se constitui também sobre a noção de instabilidade. Diante de tal quadro, Ramos (2001) adverte que a cultura coletiva e de coesão, de classe, aos poucos vai se esvaziando, crescendo o individualismo e a competição entre os trabalhadores. Nesse cenário, competência passa a ser associada à capacidade de adaptar-se às novas situações de trabalho ou de empregabilidade.

Noutros termos, se o trabalhador conseguiu um emprego, deve procurar, com a mais alta competência, atender a todas as exigências, até que um dia, em decorrência do desenvolvimento técnico, sua mão de obra não seja mais necessária ou, em decorrência da competição, sua mão de obra seja substituída por outra mais barata e rentável, voltando, assim, ao índice dos desempregados e, sentindo-se despreparado, volta aos bancos da formação profissional, limitando-se a uma solução individual para superar sua exclusão social.

Dessa forma, ocorre uma ressignificação da formação pragmática e tecnicista das décadas anteriores, em que a formação do trabalhador passa a ser compreendida como capacidade de se adequar à competição industrial, característica da produção flexível. Nesse processo, segundo Shiroma, Moraes e Evangelista (2000, p. 66), para "[...] resolver a tensão entre a vertigem provocada pela mundialização e a necessidade de referências e raízes", um movimento de reformas internacionais é pensado para a educação escolar do século $X X I$, em que se busca potencializar os indivíduos às demandas do conhecimento, ao passo que visa responder aos problemas sociais, culturais, políticos e ecológicos gerados pela exploração capitalista. Diante de tais desafios, as tarefas da educação são especificadas em uma reformulação, ampliando os seus objetivos e redimensionando o seu potencial.

Todavia, o ideário de reforma educacional que pressupunha romper com a exclusão, paradoxalmente, nem ao menos conseguiu dirimir as diferenças sociais no acesso ao conhecimento escolar. Moraes (2003), ao discorrer sobre as derivações das políticas educacionais da década de 1990, destaca que:

Para alguns, exigem-se niveis crescentemente altos de aprendizagem, situados em um domínio teórico-metodológico que a experiência empírica, por si só, é incapaz de garantir. Para maioria, porém, bastam as competências no sentido genérico que o termo adquiriu nos últimos anos, as quais permitem a sobrevivência nas franjas de um mercado de trabalho com exigências diferenciadas e níveis de exclusão jamais vistos na história. (MORAES, 2003, p. 152). 
0 discurso da progressiva universalização/democratização do Ensino Médio, apesar de se colocar como contraponto aos problemas educacionais e ao desemprego estrutural, vinculado aos interesses da reprodução do capital, traduziu-se na apologia da competitividade e da empregabilidade, responsabilizando o indivíduo pelo seu fracasso. Nesse processo, atesta-se a convergência de um consenso que responsabiliza unicamente o indivíduo por suas mazelas, ocultando a obrigação do Estado, ou seja,

\footnotetext{
[...] a ação do Estado não mais se relaciona à garantia de oportunidades de acesso a diferentes formas de trabalho; ele se desobriga da responsabilidade sobre o elo material entre os homens e sua condição de vida. Esse elo, representado pelo trabalho, passa a depender do próprio trabalhador, mais especificamente de potencialidades que thes sejam próprias. A ação estatal se limita a estimular os sujeitos para que desenvolvam suas potencialidades, parecendo resultar numa espécie de "psicologização" da ação do Estado e da correlata individualização das políticas de trabalho. (CÊA, 2007, p. 64).
}

Os discursos reformistas predominantes entre as políticas governamentais, principalmente neste início do século XXI, centraram-se na gestão escolar, buscando atender, entre outros indicativos, aos dos organismos internacionais e das avaliações em larga escola. Nessas circunstâncias, a escola perdeu espaço na autonomia de formulação de seu projeto político-pedagógico, como afirmam Silva e Ramos (2018, p. 14),

As politicas educacionais baseadas na avaliação por resultados interferem na dinâmica escolar, mediante a redução da autonomia da escola na formulação e no desenvolvimento do seu projeto político-pedagógico, até mesmo no sentido de identificar e enfrentar os limites impostos pelas condições estruturais da própria escola e de seus sujeitos.

Nesse processo, a educação de qualidade para a democracia limitou-se à ampliação da oferta escolar, sem verificar as condições materiais necessárias para suprir a carência econômica e cultural dos excluídos. No caso, as reformas ficaram limitadas à economia de tempo e de dinheiro do mercado capitalista, traduzindo-se em escolas carentes de recursos pedagógicos e humanos, limitando-se à oferta dos conhecimentos básicos necessários para formar o trabalhador e/ou o consumidor, como: as noções de matemática, de higiene, de leitura e escrita e de habilidades favoráveis ao mercado de trabalho. Em termos gerais, as políticas governamentais vieram associadas à construção de uma hegemonia em torno da mercantilização do conhecimento. 
minando o senso comum, cooptando intelectuais e formadores de opinião pública. Às ocultas, progressivamente, busca-se impor a mercantilização da educação. (SHIROMA; MORAES; EVANGELISTA, 2000, p. 115).

Verifica-se, porém, que, apesar de todas as sucessivas reformas educacionais, ainda hoje, com mais de 30 anos da chamada abertura politica, os problemas educacionais, como apontados no início desta análise, permaneceram, principalmente entre a população mais carente. Mais que isso, verifica-se que os índices de pobreza e de desemprego continuam altos. Segundo os dados divulgados pela Pesquisa Nacional por Amostra de Domićlios Contínua (PnadC), do IBGE (2017b), cerca de 22 milhões brasileiros vivem na pobreza, enquanto o número de desempregados no primeiro trimestre de 2017 era de, aproximadamente, 14,2 milhões, o que equivale a $13,7 \%$ da população economicamente ativa que procuravam emprego. Já o total de pessoas sem ocupação era mais dramático ainda, pois, "Ao todo, são 267,7 milhões de pessoas nessas condições, o maior contingente desde o início da série histórica, em 2012." (PAMPLONA, 2018).

Isso implica um contingente muito alto de pessoas pressionadas a aceitar as condiç̃̃es de trabalho "mais flexíveis". Segundo Harvey (2002, p. 143):

\footnotetext{
0 mercado de trabalho, por exemplo, passou por uma radical reestruturação. Diante da forte volatilidade do mercado, do aumento da competição e do estreitamento das margens de lucro, os patrões tiraram proveito do enfraquecimento do poder sindical e da grande quantidade de mão-deobra excedente (desempregados ou subempregados) para impor regimes e contratos de trabalho mais flexíveis [...] Mais importante do que isso, é a aparente redução do emprego regular em favor do crescente uso do trabalho em tempo parcial, temporário ou subcontratado.
}

No geral, os dados indicam que é falaciosa a tese de que a formação de qualidade para o trabalho poderia contribuir para a redução da desigualdade e da pobreza, como as politicas educacionais, com apoio do Banco Mundial, vêm preconizando. Olhando para o processo de constituição da sociedade capitalista recente, verifica-se que a miséria e o desemprego permanecem, mostrando-se como um problema estrutural do capitalismo. Segundo Deitos (2006, p. 6), a educação foi tomada "[...] como mito e mote para a redenção nacional, acobertando as contradições do processo do desenvolvimento econômico, industrial e tecnológico."

Entretanto, mesmo diante da contínua crise do capitalismo e de suas contradições estruturais, recentemente, mais uma vez, as críticas voltam para a educação. Entretanto, com uma nova roupagem, talvez, até mais perversa. Agora, a crítica é voltada para a gestão do Estado, pontuado que o problema da educação está no alto nível dos gastos. Nesse sentido, 
o relatório do Banco Mundial afirma: “Considerando o alto nível dos gastos, [...] essa redução indica que a política fiscal não é muito eficaz na redução da desigualdade no Brasil." (HIGGINS; PEREIRA, 2013 apud BANCO MUNDIAL, 2017, p. 29).

Crítica semelhante é voltada para a gestão educacional. Assim, Maria Helena Guimarães de Castro, Secretária executiva do Ministério da Educação, sob a tutela do Ministro Mendonça Filho, em entrevista aos repórteres Bárbara Santos e Marcelo Ribeiro da Revista Exame, em 6 de dezembro de 2016, afirma que seria possivel melhorar os números "[...] se as políticas públicas funcionarem."

Na mesma entrevista, a Secretária executiva do Ministério afirma que “É preciso investir na formação dos professores, nos materiais de apoio, nos materiais didáticos e nas plataformas digitais", e prossegue indicando que:

\footnotetext{
[...] os alunos não têm aprofundamento em nenhuma área. 0 que estamos propondo com a reforma do ensino médio é garantir uma base curricular nacional comum, que vai melhorar a qualidade do conjunto do sistema de ensino fundamental e médio, além do aprofundamento nas áreas e estudo para que $\circ$ aluno possa continuar sua formação geral e aprender mais. (CASTRO, 2016 apud SANTOS; RIBEIR0, 2016).
}

A crítica à má gestão do orçamento público tem sido recorrente e tem ganhado adesão de alguns especialistas, inclusive entre os da Educação. Neste aspecto, críticas também têm sido feitas ao elevado índice de reprovação e evasão escolar, apontando que "Isso parece ser a principal causa dos altos custos por formando do ensino médio no Brasil, que são bem mais elevados que em qualquer outro país da América Latina." (BANCO MUNDIAL, 2017, p. 126).

Contracenando com essas críticas, também se aponta a baixa qualidade dos professores, como um dos fatores responsáveis pela baixa qualidade da educação. Conforme Relatório do Banco Mundial (2017, p. 127): 
a um grande número de professores que irão se aposentar nos próximos anos, permitirá uma maior seleção na contratação de um número menor de professores que serão necessários para substituir os que estarão se aposentando.

Analisando esses argumentos, verifica-se que a retórica da desqualificação docente já estava anunciada nos documentos dos organismos multilaterais e nacionais da década de 1990, sendo recuperada com maior ênfase na reforma da gestão escolar como indicativo para otimizar os recursos financeiros e pedagógicos. Entretanto, diante da crise estrutural global do capitalismo, a qual tem mantido uma parcela significativa da população excluida dos bens sociais, é necessário questionar qual é o sentido de tais críticas. As reformas educacionais brasileiras fundamentadas nos pressupostos liberais, principalmente nos renomados pressupostos da Teoria do Capital Humano, dissimulam os mecanismos de exclusão do sistema educacional, bem como camuflam a exclusão inerente à competição econômica. A defesa de mudança por meio da educação, não rompeu com as determinações do capital e suas lastimáveis consequências na alienação do sujeito.

Assim, ao contrário do que consta no Relatório do Banco Mundial (2017), verifica-se que no Estado brasileiro, na gestão dos seus recursos financeiros, nem sempre a educação foi prioridade. Ou seja, há um descompasso entre o que se propala para conquistar uma educação de qualidade para a democracia e o que se efetiva na prática. Mesmo considerando as peculiaridades de cada país, não dá para deixar de ponderar que os valores destinados para a Educação no Brasil são inferiores aos do México e da Nova Zelândia. Sobre essa questão o relatório da Organisation for Economic Co-operation and Development (2015, p. 5) explicita que:

\footnotetext{
0 Brasil destina $17.2 \%$ dos seus gastos públicos à educação, do nível de educação básica à educação superior. Somente o México e a Nova Zelândia - ambos com 18,4\% - destinam uma proporção maior dos gastos públicos às instituições de ensino. Além disso, o gasto público em instituições de educação superior como percentual do gasto público total aumentou $49 \%$ entre 2005 e 2012, o que é bem acima do aumento médio da OCDE de 33\%. 0 aumento foi ainda mais acentuado em instituições de ensino fundamental e médio. A proporção de gasto público nesses níveis aumentou $82 \%$ no mesmo período, o maior aumento entre todos os países e parceiros da OCDE com dados disponiveis.
}

No que se refere à remuneração de pessoal, o que é pago no País está bem abaixo da média de outros países, pois, 
No Brasil, as instituições de educação básica destinam um percentual abaixo da média para os seus gastos com remuneração de pessoal. Para os anos iniciais do ensino fundamental, cerca de $73 \%$ das despesas correntes são destinadas à remuneração de pessoal, bem abaixo da média OCDE de $79 \%$ e um padrão semelhante se repete nos anos finais do ensino fundamental e no ensino médio. (ORGANISATION FOR ECONOMIC CO-OPERATION AND DEVELOPMENT, 2015, p. 7).

Logo em seguida registra a Organisation for Economic Co-operation and Development $(2015$, p. 7) que:

\begin{abstract}
Embora não haja uma relação direta, esses valores podem refletir o nivel dos salários dos professores dessas etapas de educação no Brasil. Salários iniciais para professores com qualificação mínima são os mesmos para cada nivel desde a pré-escola até o ensino médio e estão entre os mais baixos para todos os países e parceiros da OCDE com dados disponiveis. A média de salário inicial para professores da pré-escola entre os paises da OCDE é mais do que o dobro do que os professores ganham no Brasil e a diferença cresce nos níveis mais elevados de educação. Os salários iniciais dos professores no Brasil também são menores do que em outros países latino-americanos como Chile, Colômbia e México para todos os níveis educacionais, desde a pré-escola até o ensino médio. É importante notar, no entanto, que esses salários referem-se ao piso salarial estabelecido por lei federal - os salários reais podem variar amplamente entre os diferentes estados e municípios.
\end{abstract}

No mesmo documento, essa Organização adverte que, no Brasil, o número de estudantes por professor é bem superior do que em outros países.

\begin{abstract}
Além dos baixos salários, a baixa parcela de gastos com remuneração de pessoal também reflete o fato do Brasil ter relativamente mais estudantes por professor em todos os níveis educacionais. São 21 alunos por professor nos anos iniciais do ensino fundamental, 17 nos anos finais do ensino fundamental e ensino médio, e 27 em educação superior, todos os índices no Brasil são consideravelmente acima das respectivas médias. (ORGANISATION FOR ECONOMIC CO-OPERATION AND DEVELOPMENT, 2015, p. 8).
\end{abstract}

A exclusão social e educacional no Brasil, só tem crescido. Nesse sentido, analisando os dados pontuados pela Conferência Nacional de Educação (2010), verifica-se que existe uma lacuna entre a intenção de ampliar as oportunidades educacionais e os números de brasileiros fora da escola. Conforme os dados da Conae de 2010: 
[..] Basta identificar que, da população com mais de sete anos, $11,2 \%$ é analfabeto/a, dos/das quais aproximadamente 2,5 milhões estão na faixa de escolaridade obrigatória ( 7 a 14 anos). Dentre os/as maiores de dez anos, 11,2\% não têm escolaridade ou estiveram na escola pelo período de até um ano; $27,5 \%$ têm até três anos de escolaridade; e mais de $2 / 3$ da população $(60,4 \%)$ não possuem o ensino fundamental completo, tendo, no máximo, sete anos de escolaridade [...] (BRASLL, 2010, p. 19).

0 quadro social e educacional juvenil no Brasil é bastante preocupante para não dizer dramático. A população infantil e juvenil, estando ou não na escola, precisa de atenção e de políticas educacionais materializadas em ações efetivas, conforme apontado pelas metas do PNE (BRASIL, 2010). Neste momento, em razão das políticas macroeconômicas e fiscais, suspensas e possivelmente sem condição alguma de serem atingidas, dadas as condições estabelecidas pela política de ajuste fiscal que atende aos beneficiários do capital, o quadro de exclusão tem-se tornando cada vez mais contundente.

\section{CONSIDERAÇÕES FINAIS}

Os discursos que sustentaram/sustentam as reformas para o Ensino Médio não podem ser analisados pela inadequação/adequação da política, nem pela intenção de renovação ou de ruptura em relação aos contextos anteriores ao da Ditadura Militar. É necessário considerar as mudanças do processo de reestruturação produtiva em curso, as exigências ocupacionais e técnicas do mercado de trabalho, a interferência crescente dos organismos internacionais no interesse de manter o lucro do capital e, também, a quantidade de pessoas que continuam excluídas dos bens sociais, permanecendo e ampliando as diferenças sociais.

No geral, as reformas educacionais visaram responder a dois aspectos: a) a existência de um processo de mudança tecnológica e de crise do capital que exigiu reformas educacionais na direção de estabelecer maior controle ideológico e social; b) as renovações curriculares seguiram as diretrizes exigidas pelo capital nacional e internacional, isto, de modo a manter as condições de reprodução do capitalismo. No caso, os dados analisados indicaram que uma educação de qualidade para a democracia permaneceu na base do discurso e, semelhante ao que ocorreu no período da Ditadura Militar, preservou a exclusão da população mais pobre. Assim, a educação para empregabilidade/democracia se tornou força homogeneizadora social e, neste aspecto, serviu para dissimular as diferenças sociais estruturais, ao passo em que, pelo mito da meritocracia, legitimou a exclusão social. 
Nesse sentido, verifica-se uma incoerência entre o que se pressupõe como educação para a democracia e o que se efetiva em oferta de condições estruturais para que todos tenham acesso e permanência iguais no sistema escolar. Com raras exceções, as políticas educacionais efetivadas ao longo dos últimos 30 anos limitaram-se às necessidades e aos interesses da sociedade burguesa. No caso, apesar de apontar a educação como um veículo para a democracia, as reformas se restringiram na perspectiva de formar o trabalhador para as exigências do mercado de trabalho, servindo de instrumento de conformação social.

Reitera-se, portanto, que na análise da política educacional brasileira precisam ser consideradas as condições reais oferecidas aos jovens trabalhadores em situação de pobreza. Os discursos que buscam dissimular a educação como produto das forças econômicas e políticas hegemônicas contribuem para confirmar/conformar a adesão às metas dos organismos internacionais.

$\mathrm{Na}$ perspectiva de uma efetiva transformação das relações sociais, cabe aos educadores um papel de compromisso com os processos de ensino e de aprendizagem e, também, com a crítica das estruturas que determinam as políticas educacionais.

Assim, a defesa da função social da escola para a democracia está associada ao processo histórico-crítico do conhecimento, o que exige o conhecimento da realidade segundo as exigências/necessidades objetivas e subjetivas para a emancipação humana.

\section{REFERÊNCIAS}

ANTUNES, R. Os sentidos do trabalho. São Paulo: Boitempo, 1999.

BANCO MUNDIAL. Relatório n. 20475-BR. 0 combate à pobreza no Brasil: relatório sobre pobreza, com ênfase nas políticas voltadas para a redução da pobreza. Volume I. Departamento do Brasil - Setor de Redução da Pobreza e Manejo Econômico. Região da América Latina e do Caribe. Washington, DC, 2001.

BANCO MUNDIAL. Um ajuste justo: análise da eficiência e equidade do gasto público no Brasil. Washington, DC: BIRD/Banco Mundial, 2017. Disponivel em: http://documents.worldbank.org/curated/ en/884871511196609355/pdf/121480-REVISED-PORTUGUESE-Brazil-Public-Expenditure-Review-Overview-Portuguese-Final-revised.pdf. Acesso em: 10 dez. 2017.

BOBBIO, N.; MANTEUCCI, N.; PASQUINO, G. Dicionário de política. São Paulo: Ed. UNB, Imprensa Oficial, 2000.

BRASIL. Ministério da Educação. Conferência Nacional de Educação - CONAE 2010. Brasília, DF: CONAE, abr. 2010. 
CÊA, G. S. S. A formação do ser social trabalhador no Brasil: ethos, modus e sapere. In: CÊA, G. S. S. (org.). 0 estado da arte da formação do trabalhador no Brasil: pressuposto e ações governamentais a partir dos anos 90. Cascavel: EDUNIOESTE, 2007. p. 33-79.

CHASIN, J. A miséria da República dos Cruzados. Revista Ensaio, São Paulo, n. 15-16, p. 1-12, 1986.

DEITOS, M. L. M. S. As políticas públicas de qualificação de trabalhadores e suas relações com a inovação tecnológica na indústria brasileira. 2006. 276 f. Tese (Doutorado em Educação) - Universidade Estadual de Campinas, Campinas, 2006.

DEITOS, R. A. 0 capital financeiro e a educação no Brasil. 2005. 357 f. Tese (Doutorado em Educação) Faculdade de Educação, Universidade Estadual de Campinas, Campinas, 2005.

ENSINO SUPERIOR EM NEGÓCIOS, DIREITO E ENGENHARIA. Panorama Nacional Brasileiro: Centro de Políticas Públicas do Insper, 2017. Disponivel em: https://www.insper.edu.br/wp-content/uploads/2012/05/20170407_panorama-educacional-brasileiro2016.pdf. Acesso em: 10 nov. 2017.

FAGNANI, E. Ajuste econômico e financiamento da política social brasileira: nota sobre o período 1993/98. Revista de Economia e Sociedade, Campinas, n. 13, p. 155-178, dez. 1999.

FIORI, J. L. Em busca do dissenso perdido: ensaios críticos sobre a festejada crise do Estado. Rio de Janeiro: Insight, 1995.

FOLHA DE SÃO PAULO. 1968 - Ato Institucional n. 5: os personagens. Antônio Delfim Netto. 2008. Disponivel em: https://wwwl.folha.uol.com.br/folha/treinamento/hotsites/ai5/personas/delfimNetto.html. Acesso em: 10 out. 2017.

FRIGOTTO, G.; CIAVATTA, M.; RAMOS, M. (org.). Ensino médio integrado: concepções e contradições. 2. ed. São Paulo: Cortez, 2010.

GARCIA, S. R. O. A educação profissional integrada ao ensino médio no Paraná: avanços e desafios. 2009. Tese (Doutorado em Educação) - Universidade Federal do Paraná, Curitiba, 2009.

GERMANO, J. W. Estado militar e educação no Brasil. São Paulo: Cortez, 1994.

HARVEY, D. Condição pós-moderna. 11. ed. Tradução Adail Ubirajara Sobral e Maria Stela Gonçalves. São Paulo: Edições Loyola, 2002.

IBGE. PNAD Contínua 2016: 51\% da população com 25 anos ou mais do Brasil possuíam apenas o ensino fundamental completo. Agência de notícias do IBGE, 2017a. Disponível em: https://agenciadenoticias. ibge.gov.br/agencia-noticias/2013-agencia-de-noticias/releases/18992-pnad-continua-2016-51-da-populacao-com-25-anos-ou-mais-do-brasil-possuiam-apenas-o-ensino-fundamental-completo.html. Acesso em: 22 dez. 2017. 
IBGE. PNAD Contínua: taxa de desocupação cai em 11 das 27 UFs no $2^{\circ}$ trimestre de 2017 . Agência de notícias do IBGE, 2017b. Disponível em: https://agenciadenoticias.ibge.gov.br/agencia-noticias/2013-agencia-de-noticias/releases/15693-pnad-continua-taxa-de-desocupacao-cai-em-11-das-27-ufs-no-2-trimestre-de-2017.html. Acesso em: 30 out. 2017.

INSTITUTO DE PESQUISA ECONÔMICA APLICADA. Educação no Brasil: atrasos, conquistas e desafios. 2006. Disponivel em: http://www.ipea.gov.br/bd/pdf/2006/cap3_educacao.pdf. Acesso em: 12 dez. 2017.

INSTITUTO NACIONAL DE ESTUDOS E PESQUISAS EDUCACIONAIS ANÍSIO TEIXEIRA. Censo escolar da educação básica - 2016. Notas estatísticas. Brasilia, DF: INEP/MEC, 2017. Disponivel em: http://download.inep. gov.br/educacao_basica/censo_escolar/notas_estatisticas/2017/notas_estatisticas_censo_escolar_da_educacao_basica_2016.pdf. Acesso em: 11 out. 2017.

INSTITUTO NACIONAL DE ESTUDOS E PESQUISAS EDUCACIONAIS ANISIO TEIXEIRA. Ministério da Educação e Cultura. Censo Escolar 1980/2000. Edudata Brasil; IBGE, Censo Demográfico. Brasília, DF: INEP/MEC, 2001. Disponível em: https://seriesestatisticas.ibge.gov.br/series.aspx? 2 codigo=SEE17. Acesso em: 8 out. 2017.

INSTITUTO NACIONAL DE ESTUDOS E PESQUISAS EDUCACIONAIS ANISIO TEIXEIRA. Ministério da Educação e Cultura. Sistema de avaliação da educação básica - 2015. Resumo. Brasilia, DF: INEP/MEC, 2016. Disponivel em: http://www.brasil.gov.br/educacao/2016/09/inep-apresenta-resultados-da-prova-brasil-2015. Acesso em: 14 nov. 2017.

LAURELL, A. C. Avançando em direção ao passado: a política social do neoliberalismo. In: LAURELL, A. C. (org.). Estado e políticas sociais no neoliberalismo. Revisão Técnica Amélia Cohn; Tradução Rodrigo León Contrera. 3. ed. São Paulo: Cortez, 2002. p. 151-178.

MORAES, M. C. M. Recuo da Teoria. In: MORAES, M. C. M. de. (org.). lluminismo às avessas: produção de conhecimento e políticas de formação docente. Rio de Janeiro: DP \& A, 2003. p. 151-167.

MORENO, A. C. Brasil cai em ranking mundial de educação em ciências, leitura e matemática. G1, 06 dez. 2016. Disponível em: https://gl.globo.com/educacao/noticia/brasil-cai-em-ranking-mundial-de-educacao-em-ciencias-leitura-e-matematica.ghtml. Acesso em: १1 out. 2017.

MOTA JUNIOR, W. P.; MAUÉS, O. C. 0 Banco Mundial e as políticas educacionais brasileiras. Educação \& Realidade, Porto Alegre, v. 39, n. 4, p. 1137-1152, 2014. Disponível em: http://2011.redalyc.org/articulo. oa:id=317232121010. Acesso em: 8 out. 2017.

ORGANISATION FOR ECONOMIC CO-OPERATION AND DEVELOPMENT. Education At a Glance 2015. 2015. Disponivel em: https://www.oecd.org/brazil/Education-at-a-glance-2015-Brazil-in-Portuguese.pdf. Acesso em: 8 out. 2017. 
OSHMA, F. Y. OCDE revela que mais da metade dos adultos brasileiros não tem ensino médio. Revista Época, Rio de Janeiro, 24 nov. 2015. Disponível em: http://epoca.globo.com/vida/noticia/2015/11/ocde-revela-que-mais-da-metade-dos-adultos-brasileiros-nao-tem-ensino-medio.html. Acesso em: 21 dez. 2017.

PAMPLONA, N. Falta trabalho para 27,7 milhões de pessoas, diz IBGE. Folha de São Paulo, 2018. Disponivel em: https://wwwl.folha.uol.com.br/mercado/2018/05/falta-trabalho-para-277-milhoes-de-pessoas-diz-ibge.shtml. Acesso em: 17 maio 2018.

RAMOS, M. N. A Pedagogia das competências: autonomia ou adaptação? São Paulo: Cortez, 2001.

SANTOS, B. F.; RIBEIRO, M. 0 Brasil está entre os piores em ranking mundial de educação. Revista Exame, 2016. Disponível em: https://exame.abril.com.br/brasil/brasil-esta-entre-os-8-piores-em-ciencias-em-ranking-de-educacao/. Acesso em: 23 nov. 2017.

SAVIANI, D. Sobre a concepção de politecnia. Rio de Janeiro: EPSJV/FIOCRUZ, 1989.

SHIROMA, E. 0.; MORAES, M. C. M.; EVANGELISTA, 0. Política educacional. Rio de Janeiro: DP\&A, 2000.

SILVA, K. N. P.; RAMOS, M. 0 ensino médio integrado no contexto da avaliação por resultados. Educação e Sociedade, p. 1-17, 2018. Disponivel em: http://www.scielo.br/pdf/es/2018nahead/1678-4626-eses0101-73302018186794.pdf. Acesso em: 23 jan. 2018.

VIEIRA, E. A. Estado e miséria social no Brasil: de Getúlio a Geisel. São Paulo: Cortez, 1983.

Endereços para correspondência: Rua Laranjeiras do Sul, n. 1350, 85.816-520, Jardim Nova York, Cascavel, Paraná, Brasil; cidafavoreto@globo.com 
